\title{
Utilization of Waste Copper Slag to Produce Directly Reduced Iron for Weathering Resistant Steel
}

\author{
Zhou XIAN-LIN, * Zhu DE-QING, Pan JIAN and Wu TENG-JIAO \\ School of Mineral Processing and Bioengineering, Central South University, Lushan South Road 932, Yuelu District, Changsha, \\ 410083 China.
}

(Received on January 5, 2015; accepted on March 26, 2015)

\begin{abstract}
Waste copper slag is a refractory material with high iron content, but it is difficult to recovery iron minerals from the slag because the iron mainly occurs in fayalite. A new technology of coal-based direct reduction-magnetic separation process was developed to recover iron from the slag assaying 39.85\% $\mathrm{Fe}_{\text {total }}$ and $0.33 \% \mathrm{Cu}$. The results show that the final iron concentrate, assaying $90.68 \% \mathrm{Fe}_{\text {total, }}$ 94.01\% metallization degree, $0.66 \% \mathrm{Cu}$ and $0.058 \% \mathrm{~S}$ with overall iron and copper recoveries of $90.49 \%$ and $79.53 \%$, respectively, was manufactured under the optimized conditions as follows: balling the mixture of copper slag with $20 \%$ compound additive at 0.3 of basicity, preheating the green pellets at $1000^{\circ} \mathrm{C}$ for $9 \mathrm{~min}$, then reducing the preheated pellets at $1200^{\circ} \mathrm{C}$ for $70 \mathrm{~min}$ with coal to dried pellets mass ratio of 2, grinding the reduced pellets up to $95 \%$ passing $0.074 \mathrm{~mm}$, and magnetically separating the ground product in Davi Tube at $0.08 \mathrm{~T}$ magnetic field intensity. The observation of the reduced pellets microstructure shows that the additive plays a role of nucleating agent, which enhances metallic iron grains migrating and coarsening during reduction process. The process is probably one of efficient ways to recover iron from copper slag to produce directly reduced iron (DRI), which can be used as the burden to produce weathering resistant steel by electric arc furnace to replace sponge iron or scrap steel. The process reduces the secondary environmental pollution of copper slag and has been applied well in Tongling Nonferrous Metals Group Holding Co., Ltd in China.
\end{abstract}

KEY WORDS: waste copper slag; coal-based direct reduction; directly reduced iron; compound additive; weathering resistant steel.

\section{Introduction}

Copper slag is a waste during pyrometallurgical production of copper from copper sulfide concentrates, about 2.2 tons of which being generated per ton of metal copper production. Dumping or disposal of such huge quantities of slag causes not only secondary environmental pollution due to the high content of $\mathrm{Cu}, \mathrm{Pb}, \mathrm{Zn}$ and $\mathrm{S}$ in copper slag, but also wastes resources because of about $40 \%$ iron and some $\mathrm{Cu}, \mathrm{Pb}, \mathrm{Zn}$ occurring in copper slag. ${ }^{1)}$

Extensive researches were conducted to utilize copper slag. Various methods of recovering copper from copper slag including pyrometallurgical, hydrometallurgical, and combined pyro and hydrometallurgical processes were briefly reviewed by Gorai et al. ${ }^{2)}$ The recovery of copper by floatation from copper slag is the most effective and successful route. ${ }^{3-6)}$ However, many beneficiation processes to separate the copper from slag are not economical because of the low grade of copper. In the meantime, the slag can be directly used in other areas, such as cement, tiles, binder and so on. ${ }^{2}$ Using of copper slag as a Portland cement replacement was reported by several researchers. ${ }^{7-9)}$ It affects the strength and toughness of the mixture. Recover of value

\footnotetext{
* Corresponding author: E-mail: xlzhou_csu@csu.edu.cn
} DOI: http://dx.doi.org/10.2355/isijinternational.55.1347 metals by ammonium chloride treatment was proposed by Nadirov et al. ${ }^{10)}$ Few literatures about recovering iron from copper slag were reported, because it is difficult to extract iron from the slag by traditional processes, where iron mainly exists in fayalite $\left(\mathrm{Fe}_{2} \mathrm{SiO}_{4}\right)$. Cheng et al. developed a method to directly upgrade iron from the slag. ${ }^{11)}$ However, no results of iron grade and recovery were reported. Kim et al. carried out a research on reduction-magnetic separation process, where reduction at $1250^{\circ} \mathrm{C}$ for $1.5 \mathrm{~h}$ and then followed by dry magnetic separation to recover iron from the copper slag of Korea Zinc Co., Ltd., but the grade of product is low and $\mathrm{SiO}_{2}$ content is as high as $12.7 \%{ }^{12)} \mathrm{Li}$ et al. extracted the iron by deep reduction at $1300^{\circ} \mathrm{C}$ for $3 \mathrm{~h}$ and magnetic beneficiation, producing iron powder containing 96.21\% Fe $_{\text {total. }}{ }^{13)}$

Direct reduction is one of effective technologies to process the secondary resources containing ferrous. Due to the lack of natural gas, coal-based direct reduction is the preferentially considered technique in China. Coal acts as not only exothermal agent but also reductant, and deoxidation reactions are completed in rotary kiln or tunnel kiln. ${ }^{14,15)}$ Therefore, an innovative technology of recovering iron from copper slag by a coal-based direct reduction and magnetic separation process was developed in this paper. 


\section{Material and Methods}

\subsection{Raw Materials}

The chemical compositions of copper slag used in this study are given in Table 1. The total iron content of copper slag is $39.85 \%$, and the content of $\mathrm{SiO}_{2}, \mathrm{Cu}, \mathrm{Pb}$ and $\mathrm{Zn}$ are $30.81 \%, 0.33 \%, 0.22 \%$ and $2.81 \%$, respectively. The minerals of copper slag determined by X-ray diffraction (XRD) are mainly fayalite and magnetite, as shown in Fig. 1. Figure 2 presents representative SEM-EDS micrographs of copper slag sample, which indicates that fayalite and magnetite are the main minerals in slag, and they are closely combined with copper matte and glassy minerals. Sphalerite is found jointed with copper matte. The size of copper slag is $84.28 \%$ and $96.74 \%$ passing $0.044 \mathrm{~mm}$ and $0.074 \mathrm{~mm}$, respectively.

Limestone containing $60.38 \%$ of $\mathrm{CaO}$ and $37.47 \%$ of loss of ignition (LOI) was used to adjust the basicity of blends.

The compound additive containing $16.38 \%$ of hematite, $41.45 \%$ of magnetite and $35.18 \%$ of LOI was produced by Central South University, in a form of powder with over 90\% passing $0.074 \mathrm{~mm}$.

Table 1. Chemical compositions of copper slag by mass (\%).

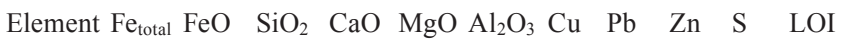

Content $\begin{array}{lllllllllll}39.85 & 43.68 & 30.81 & 2.00 & 1.28 & 2.83 & 0.33 & 0.22 & 2.81 & 0.18 & 0.19\end{array}$

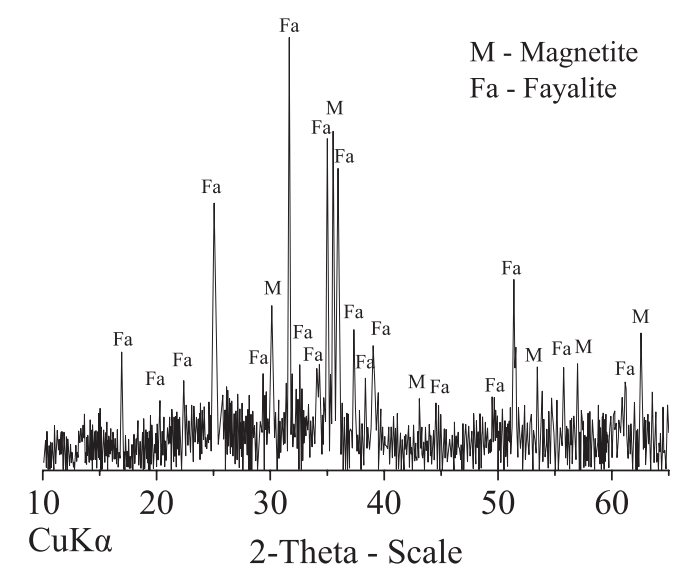

Fig. 1. X-ray diffraction pattern of copper slag.
The soft coal was used as reductant agent, with fixed carbon of $52.12 \%$ on air dry basis (FCad), volatile matter of $30.41 \%$ on dry ash free (Vdaf), ash of $4.49 \%$ on air dry basis (Aad), $0.58 \%$ of S and melting temperature of $1376^{\circ} \mathrm{C}$. The size of soft coal is $100 \%$ passing $3 \mathrm{~mm}$.

\subsection{Experimental Methods}

The experimental flow sheet includes procedures as follows: mixing the copper slag with additive, pelletizing of mixture, preheating of dried pellets, reduction roasting of preheated pellets, grinding the reduced pellets, low intensity magnetic separation of the ground product to manufacture DRI.

Mixtures were prepared by mixing copper slag, limestone and some compound additive at a certain ratio relative to the mass of copper slag. Then pellets were prepared by balling the mixtures in a disc pelletizer of $0.8 \mathrm{~m}$ in diameter and $0.2 \mathrm{~m}$ rim depth, rotating at $38 \mathrm{rpm}$ and being inclined at $47^{\circ}$ to the horizontal. The green balls were transferred into the drying oven to dry at $105^{\circ} \mathrm{C}$ for $2 \mathrm{~h}$ until the weight unchanged.

The dried pellets were put into the corundum porcelain and were preheated in the horizontal tube, where the preheating temperature from 900 to $1100^{\circ} \mathrm{C}$ and duration from 6 to $15 \mathrm{~min}$ were investigated to get the suitable preheating conditions, and the best compressive strength of preheated pellets was $1270 \mathrm{~N} /$ pellet by preheating at $1000^{\circ} \mathrm{C}$ for 9 min.

The coal-based direct reduction was done as follows: the preheated pellets were covered with proper mass of coal in the stainless steel pot. The steel pot was put into the muffle furnace (model: KSY-12-18) while the reducing temperature was elevated to the target value. When the reduction time was ended, the hot steel pot was taken out and covered by pulverized coal to cool down quickly in the air to prevent reduced pellets from being re-oxidized.

The magnetic separation was performed in the Davis Tube (model: XCGS-73) after $20 \mathrm{~g}$ of reduced pellets being ground in the cone ball mill (model: XMQ240×90). The DRI was obtained after magnetic separation. The grinding fineness of reduced pellets was about $95 \%$ passing $0.074 \mathrm{~mm}$ and the magnetic field intensity was $0.08 \mathrm{~T}$.

The chemical compositions of copper slag and iron concentrate were measured using chemical analysis. The crys-
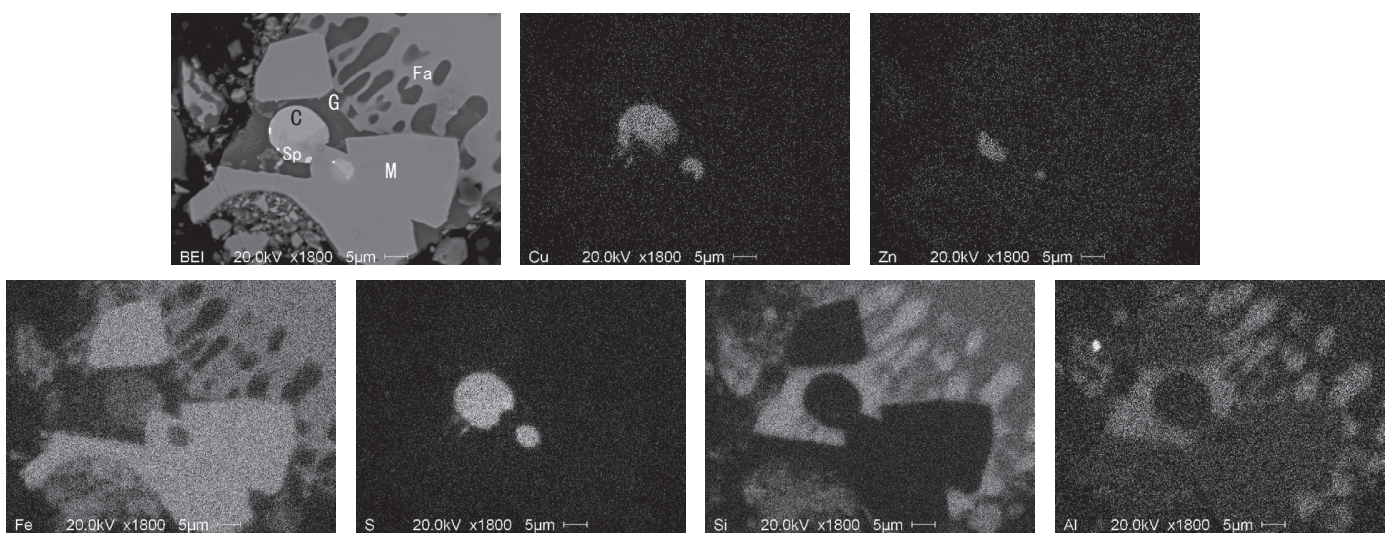

Fig. 2. Representative SEM-EDS micrographs of copper slag sample (C - Copper matte, Fa - Fayalite, $\mathrm{M}$ - Magnetite, $\mathrm{Sp}$ - Sphalerite, G - Glassy materials). 
talline phase composition of the material was investigated using X-ray diffractometer (XRD, RIGAKU, D/Max-2500). Proximate analysis of coal and determination of fusibility of coal ash were followed by GB/T212-2008 and GB/T2192008, respectively. Microstructures of reduced briquettes were analyzed by scanning electron microscope (SEM, FEI Quanta-200), and the compositional analyses were carried out using an energy dispersion system (EDAX-TSL, Ametek) within the SEM.

\section{Results and Discussion}

\subsection{Basicity}

Binary basicity was used in the tests, which is the ratio of $\mathrm{CaO} / \mathrm{SiO}_{2}$. The effect of basicity on the beneficiation of iron concentrate is presented in Fig. 3. The iron grade decreased from $71.02 \%$ to $63.52 \%$ and the iron recovery increased from $55.05 \%$ to $74.78 \%$ when basicity was elevated from 0.065 (natural basicity) to 0.9 . By adjusting the basicity, more iron was transformed to metallic iron, leading to higher recovery. But iron grains were still small (shown in Sec. 3.6) and combined with impurities, issuing in lower iron grade of concentrate.

The thermodynamics calculation results of fayalite reduction process by $\mathrm{CO}$ and adding with alkaline oxide are shown in Fig. 4. It indicates that fayalite is difficult to be

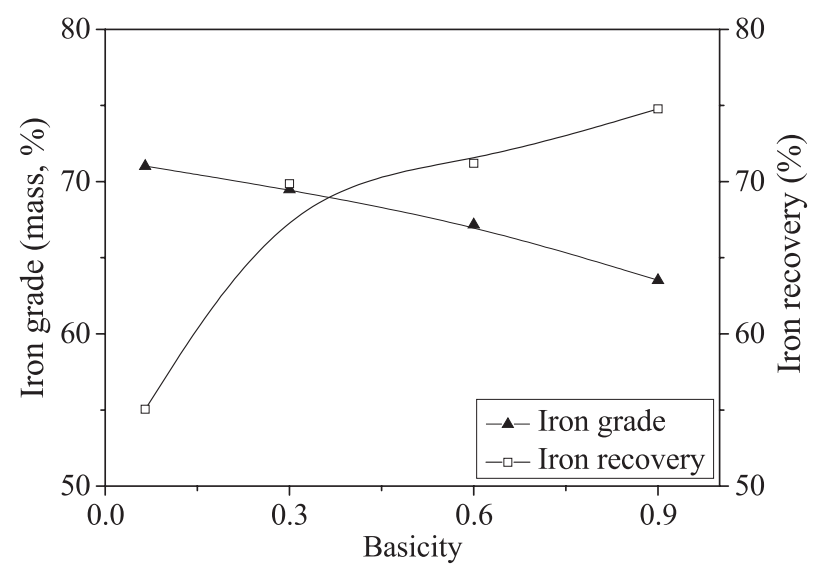

Fig. 3. Effect of basicity on the beneficiation of iron (Reducing at $1100^{\circ} \mathrm{C}$ for $70 \mathrm{~min}$ with coal to dried pellets mass ratio of 2).

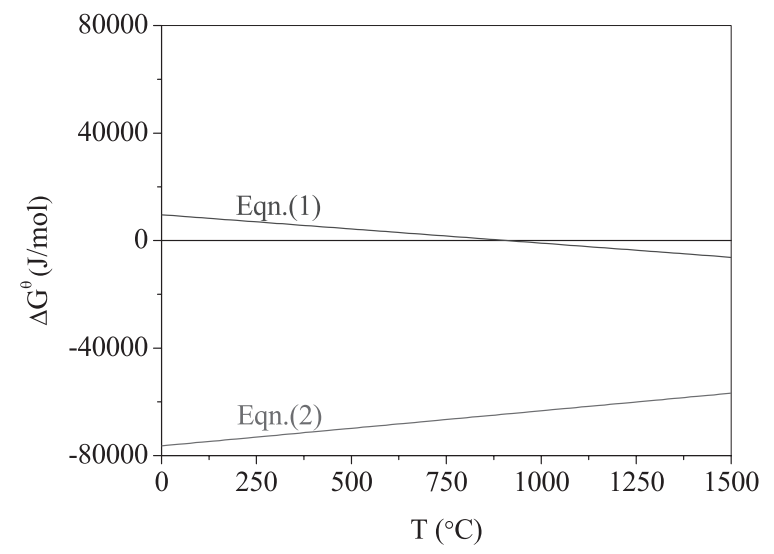

Fig. 4. Change of Gibbs free energy in direct reduction process on fayalite. reduced only by $\mathrm{CO}$ [Eq. (1)], but easier by added alkaline oxide [Eq. (2)]. $\mathrm{CaO}$ can improve the fayalite reduction by chemically combining with $\mathrm{SiO}_{2}$ to form wollastonite $\left(\mathrm{CaO} \cdot \mathrm{SiO}_{2}\right) .{ }^{11)}$ More $\mathrm{CaO}$ will help to form dicalcium silicate $\left(2 \mathrm{CaO} \cdot \mathrm{SiO}_{2}\right)$ by solid-phase reaction, which contributes to the separation of slag and iron by natural pulverization of dicalcium silicate during cooling. ${ }^{11,16)}$

$$
\begin{aligned}
& \mathrm{Fe}_{2} \mathrm{SiO}_{4}+2 \mathrm{CO}=2 \mathrm{Fe}+\mathrm{SiO}_{2}+2 \mathrm{CO}_{2} \\
& \Delta \mathrm{G}^{\theta}=12477-10.55 \mathrm{~T}
\end{aligned}
$$

$$
\begin{aligned}
& \mathrm{Fe}_{2} \mathrm{SiO}_{4}+\mathrm{CaO}+2 \mathrm{CO}=2 \mathrm{Fe}+\mathrm{CaO} \cdot \mathrm{SiO}_{2}+2 \mathrm{CO}_{2} \\
& \Delta G^{\theta}=-79956+13.06 \mathrm{~T}
\end{aligned}
$$

By consideration of iron grade and recovery, the suitable basicity was suggested at 0.3 , where the iron grade and recovery are $69.48 \%$ and $69.86 \%$, respectively. However, it can't get high quality of DRI only by adjusting the basicity, additive should be developed to enhance the reduction and grain growth of iron.

\subsection{Dosage of Additive}

Sodium salts were developed by many researchers to promote the reduction of iron from low grade and complex iron ores, such as high-aluminum limonite ore, ${ }^{17}$ ) high-phosphorus oolitic hematite ore ${ }^{18)}$ and siderite ore, ${ }^{19)}$ and good results were achieved. However, sodium salts may cause the degradation of refractory materials, ${ }^{20)}$ so a compound additive containing low impurities, mainly in iron oxides and volatile matter content, was developed to improve reduction on low grade hematite pellets. ${ }^{21,22)}$ And the additive was used in the tests of extracting iron from copper slag. Figure 5 shows the effect of additive dosage on the upgrading of iron concentrate. The compound additive can enhance upgrading the iron, leading to both higher iron grade and recovery. The iron grade was raised from $69.48 \%$ to $78.18 \%$ and iron recovery was elevated from $69.74 \%$ to $89.37 \%$ when dosage of the compound additive was augmented from $0 \%$ to $20 \%$. The indexes of iron concentrate kept unchanged when dosage of additive was beyond of $20 \%$. Therefore, the optimum dosage of additive was advised at $20 \%$.

Although additive can reinforce the indexes of iron con-

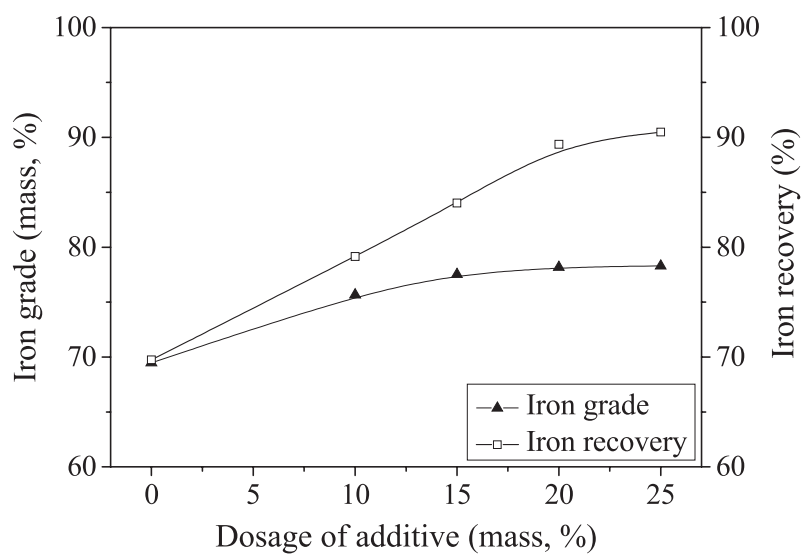

Fig. 5. Effect of dosage of additive on the beneficiation of iron ( 0.3 of basicity, reducing at $1100^{\circ} \mathrm{C}$ for $70 \mathrm{~min}$ and at coal to dried pellets mass ratio of 2). 
centrate in a certain extent, but rational temperature and duration should be optimized to extract better quality of iron powder.

\subsection{Reduction Temperature}

The effect of reduction temperature on the upgrading of iron is illustrated in Fig. 6. The iron grade raised from $78.18 \%$ to $91.16 \%$ when the reduction temperature increased from $1100^{\circ} \mathrm{C}$ to $1250^{\circ} \mathrm{C}$, and the iron recovery was over $90 \%$. Temperature is an important factor in direct reduction, and increasing temperature can obviously promote reducing reactions. The higher the reduction temperature, the higher iron grade obtained.

\subsection{Reduction Time}

The effect of reduction time on the upgrading of iron is presented in Fig. 7. When reduction time was extended from 30 to $70 \mathrm{~min}$, the iron grade increased from $74.81 \%$ to $90.68 \%$ and iron recovery enhanced from $88.56 \%$ to $90.49 \%$, and then kept steady when time was beyond of $90 \mathrm{~min}$. Metallic iron is strongly magnetic mineral, which can be easily to recover by low-intensity magnetic separation process. So that high recoveries around 90\% were achieved and didn't change much with an increase of the

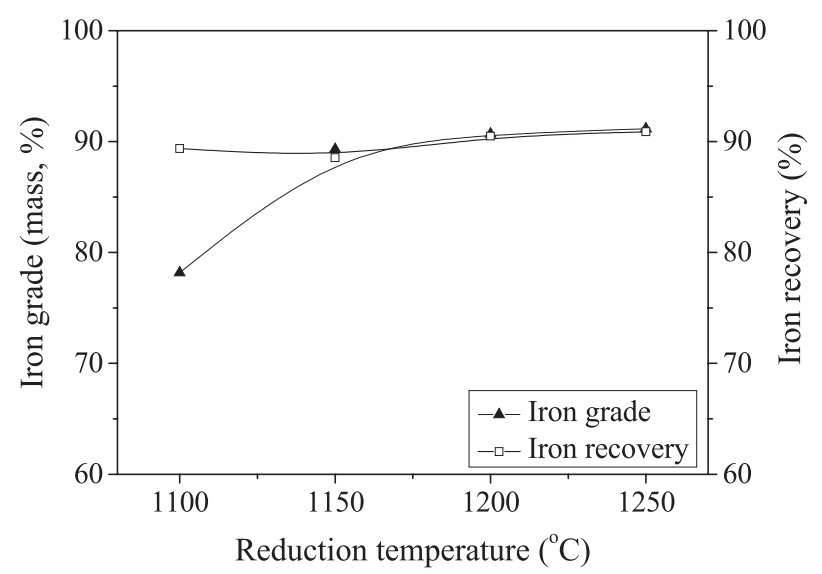

Fig. 6. Effect of reduction temperature on the beneficiation of iron ( 0.3 of basicity, blending with $20 \%$ of compound additive, reducing for $70 \mathrm{~min}$ with coal to dried pellets mass ratio of 2).

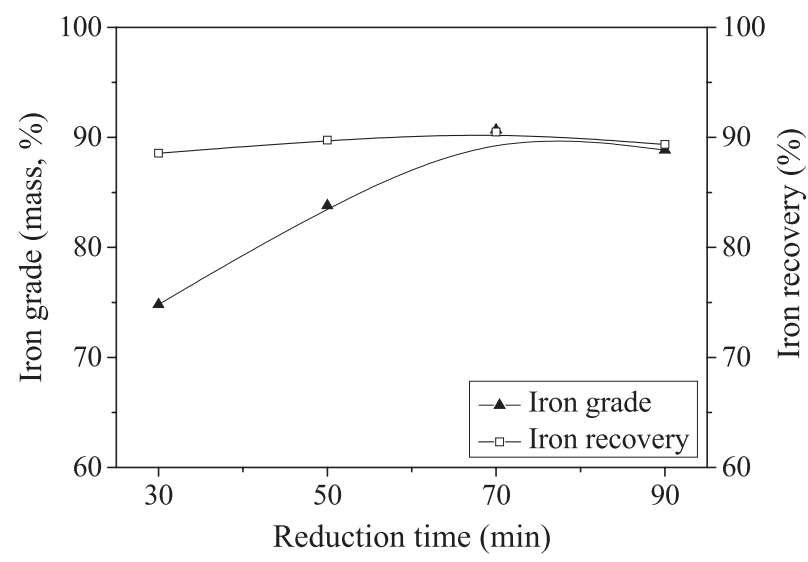

Fig. 7. Effect of reduction time on the beneficiation of iron $(0.3$ of basicity, blending with $20 \%$ of compound additive, reducing at $1200^{\circ} \mathrm{C}$ with coal to dried pellets mass ratio of 2). reduction time. Therefore, reducing for $70 \mathrm{~min}$ at $1200^{\circ} \mathrm{C}$ is recommended.

\subsection{Mass Ratio of Coal to Dried Pellets}

Table 2 summarizes the effect of mass ratio of coal to dried pellets on the concentration of iron. When coal to dried pellets mass ratio was elevated from 1 to 2 , the iron grade and recovery increased from $88.64 \%$ to $90.68 \%$ and $88.70 \%$ to $90.49 \%$, respectively. The iron grade and recovery kept steady when the ratio was beyond 2 . The ratio is higher than industrial application with a degree of $0.5-0.7$, which is similar with the research developed by Zhu et al. ${ }^{23)}$

In summary, the optimum conditions from above tests recommended were as followings: preparing the green balls by blending with $20 \%$ of compound additive and 0.3 basicity, preheating dried balls at $1000^{\circ} \mathrm{C}$ for $9 \mathrm{~min}$, reducing the preheated pellets at $1200^{\circ} \mathrm{C}$ for $70 \mathrm{~min}$ with coal to dried pellets mass ratio of 2 , and magnetic separating the ground reduced briquettes with a size up to $95 \%$ passing $0.074 \mathrm{~mm}$ at $0.08 \mathrm{~T}$ magnetic field intensity.

The chemical compositions of final iron powder are shown in Table 3. The DRI, assaying $90.68 \% \mathrm{Fe}_{\text {total }}, 94.01 \%$ metallization degree, $0.66 \% \mathrm{Cu}, 0.021 \% \mathrm{~Pb}, 0.041 \% \mathrm{Zn}$ and $0.058 \% \mathrm{~S}$ with overall iron and copper recoveries of $90.49 \%$ and $79.53 \%$, respectively, was manufactured. The final product can be used as the burden along with scrap steel for making weathering resistant steel by electric arc furnace. The process has been applied well in Tongling Nonferrous Metals Group Holding Co., Ltd in China.

\subsection{Enhance Mechanism of Compound Additive}

Figure 8 shows the microstructures of reduced pellets and chemical compositions without additive under SEM and EDS. Metallic iron grains are pure and embrace some of metal $\mathrm{Cu}$ (Phase 1 in Fig. 8). The size of metallic ferrous grains is smaller than $20 \mu \mathrm{m}$, indicating that metallic ferrous grain is difficult to be liberated from gangue minerals and effective upgraded by magnetic separation. Meanwhile, some wustite inclusions present in metallic ferrous grains (Phase 2 in Fig. 8), which affects the iron grade of DRI. According to EDS analysis (Phase 3 in Fig. 8), the main gangue mineral with an atom ratio $[\mathrm{Si}] /[\mathrm{Fe}]=1.30$ is mainly consist of ferrosilite $\left(\mathrm{FeO} \cdot \mathrm{SiO}_{2}\right.$, with an atom ratio [Si]/ $[\mathrm{Fe}]=1)$, leading to low recovery of iron.

Table 2. Effect of mass ratio of carbon to iron on the qualities of iron concentrate.

\begin{tabular}{ccc}
\hline $\begin{array}{c}\text { Mass ratio of coal } \\
\text { to dried pellets }\end{array}$ & Iron grade (mass, \%) & Iron recovery (\%) \\
\hline $1: 1$ & 88.64 & 88.70 \\
$2: 1$ & 90.68 & 90.49 \\
$3: 1$ & 90.12 & 91.19 \\
\hline
\end{tabular}

Table 3. Chemical compositions of final iron concentrate by mass $(\%)$.

\begin{tabular}{llllllllll} 
Element $\mathrm{Fe}_{\text {total }}$ & $\mathrm{Fe}_{\text {metal }} \mathrm{SiO}_{2} \mathrm{CaO}$ & $\mathrm{Al}_{2} \mathrm{O}_{3}$ & $\mathrm{Cu}$ & $\mathrm{Pb}$ & $\mathrm{Zn}$ & $\mathrm{S}$ & $\mathrm{P}$ \\
\hline
\end{tabular}

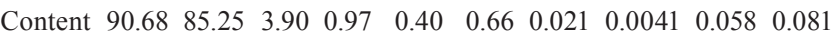



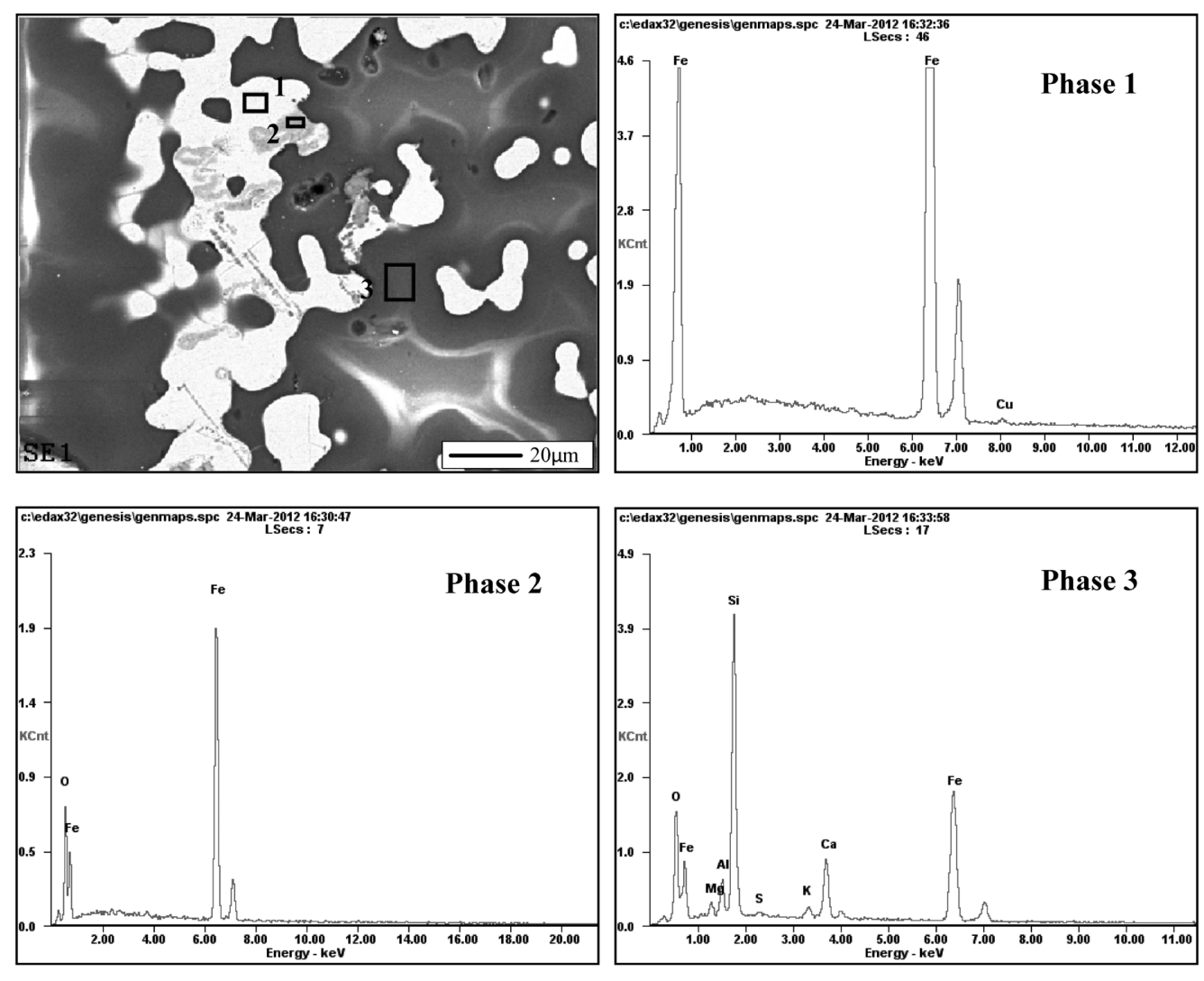

\begin{tabular}{cccccccccccc}
\hline Phase & Element & $F e K$ & $C u K$ & $O K$ & $M g K$ & $A l K$ & $S i K$ & $S K$ & KK & CaK & Matrix \\
\hline \multirow{2}{*}{$\mathbf{1}$} & $W t \%$ & 99.10 & 00.90 & $/$ & $/$ & $/$ & $/$ & $/$ & $/$ & $/$ & Correction \\
& $A t \%$ & 99.21 & 00.79 & $/$ & $/$ & $/$ & $/$ & $/$ & $/$ & $/$ & ZAF \\
\multirow{2}{*}{$\mathbf{2}$} & $W t \%$ & 85.87 & $/$ & 14.13 & $/$ & $/$ & $/$ & $/$ & $/$ & $/$ & Correction \\
& $A t \%$ & 63.52 & $/$ & 36.48 & $/$ & $/$ & $/$ & $/$ & $/$ & $/$ & ZAF \\
\multirow{3}{*}{3} & $W t \%$ & 39.21 & $/$ & 21.68 & 01.55 & 03.67 & 25.69 & 00.39 & 01.23 & 06.59 & Correction \\
& $A t \%$ & 20.77 & $/$ & 40.10 & 01.89 & 04.02 & 27.07 & 00.36 & 00.93 & 04.86 & ZAF \\
\hline
\end{tabular}

Fig. 8. SEM-EDS results of reduced pellets without additive $\left(0.3\right.$ of basicity, reducing at $1200^{\circ} \mathrm{C}$ for $70 \mathrm{~min}$ at coal to dried pellets mass ratio of 2).

By contrast, the compound additive can significantly promote the growth of metallic ferrous grains to around $50 \mu \mathrm{m}$ (Fig. 9), inferring that easy liberation and high-grade iron concentrate will be obtained by magnetic separation. The compound additive contains iron minerals of hematite and magnetite, which play a role of nucleating agent to reduce the nucleating barrier, leading to improve the aggregation and growth of metallic iron grains. ${ }^{21)}$ According to EDS analysis (Phase 2 in Fig. 9), the main gangue minerals with an atom ratio $[\mathrm{Si}] /([\mathrm{Fe}]+[\mathrm{Ca}])=1.16$ are mainly consist of wollastonite $\left(\mathrm{CaO} \cdot \mathrm{SiO}_{2}\right.$, with an atom ratio $\left.[\mathrm{Si}] /[\mathrm{Ca}]=1\right)$ and ferrosilite $\left(\mathrm{FeO} \cdot \mathrm{SiO}_{2}\right)$, but the content of ferrosilite is lower than Phase 3 in Fig. 8. Minerals of Phase 3 in Fig. 9 are similar with Phase 2.

\section{Conclusions}

(1) The copper slag, assaying $39.85 \% \mathrm{Fe}_{\text {total }}, 30.81 \%$ $\mathrm{SiO}_{2}, 0.33 \% \mathrm{Cu}, 0.22 \% \mathrm{~Pb}, 2.81 \% \mathrm{Zn}$ and $0.18 \% \mathrm{~S}$, was used as the raw materials to produce metal ferrous powder. Iron minerals mainly exist in the form of fayalite and magnetite, which are closely combined with copper matte and glassy minerals, issuing in difficult to extract iron from the slag.

(2) The final DRI, assaying $90.68 \% \mathrm{Fe}_{\text {total }}, 94.01 \%$ metallization degree, $0.66 \% \mathrm{Cu}, 0.021 \% \mathrm{~Pb}, 0.041 \% \mathrm{Zn}$ and $0.058 \% \mathrm{~S}$ with overall iron and copper recoveries of $90.49 \%$ and $79.53 \%$, respectively, was manufactured under the following conditions: pelletizing the mixture of copper slag with $20 \%$ compound additive at 0.3 of basicity, preheating the pellets at $1000^{\circ} \mathrm{C}$ for $9 \mathrm{~min}$, then reducing the preheated pellets at $1200^{\circ} \mathrm{C}$ for $70 \mathrm{~min}$ with coal to dried pellets mass ratio of 2 , grinding the reduced pellets up to $95 \%$ passing $0.074 \mathrm{~mm}$ and magnetic separation in Davi Tube at $0.08 \mathrm{~T}$ magnetic field intensity. The process reduces the secondary environmental pollution of copper slag and has been applied well in Tongling Nonferrous Metals Group Holding Co., Ltd in China.

(3) The compound additive plays a role of nucleating agent during direct reduction, which can significantly enhance the reduction of fayalite, improve metallic ferrous grains migrated and agglomerated, effectively promote the iron grains liberation in grinding, upgrading the iron degree and iron recovery in magnetic separation. Further work will be taken to verify the reduction behavior of compound additive during reduction process. 

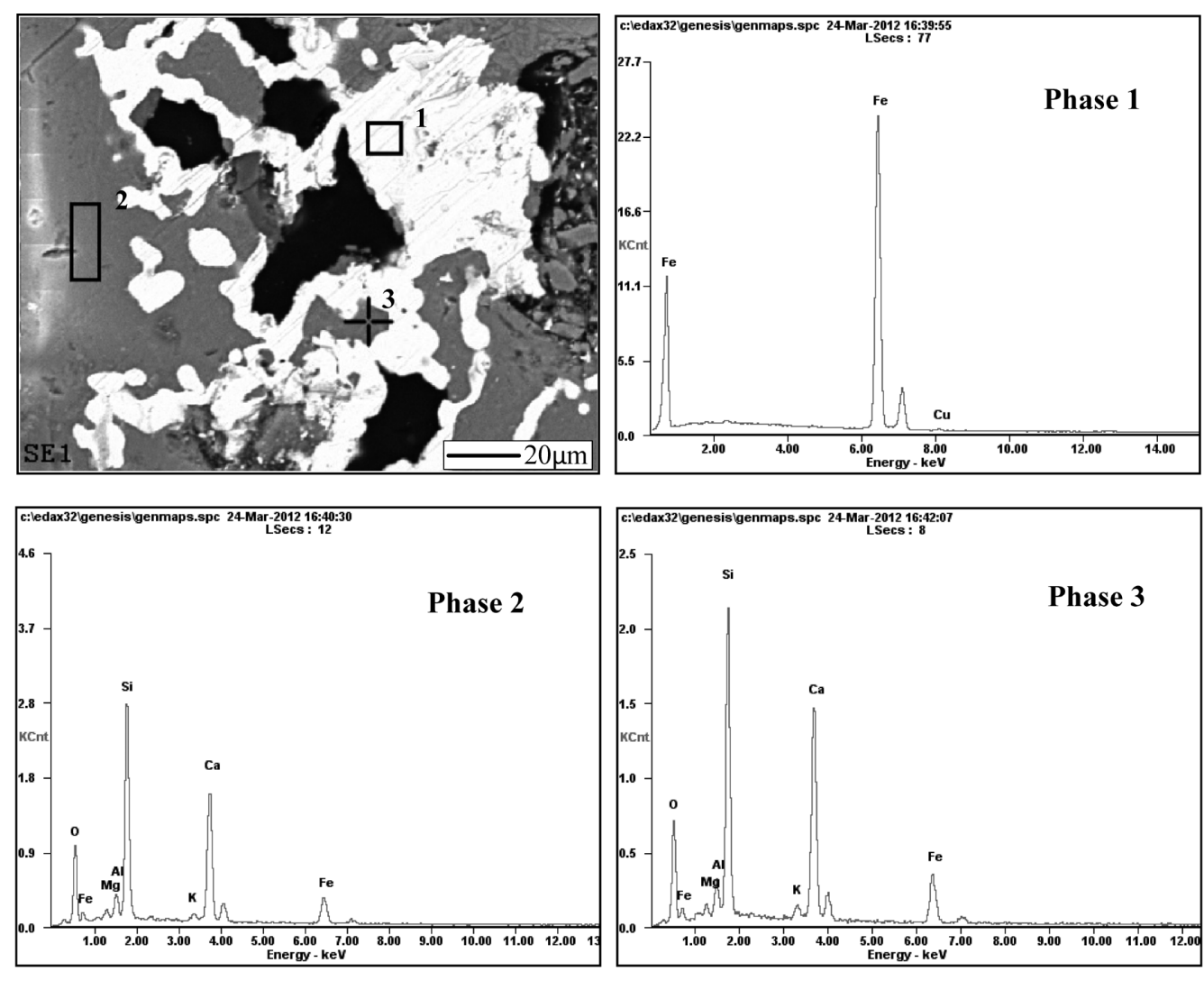

\begin{tabular}{ccccccccccc}
\hline Phase & Element & $F e K$ & $C u K$ & $O K$ & $M g K$ & $A l K$ & SiK & KK & CaK & Matrix \\
\hline \multirow{2}{*}{$\mathbf{1}$} & $W t \%$ & 98.84 & 01.16 & $/$ & $/$ & $/$ & $/$ & $/$ & $/$ & Correction \\
& $A t \%$ & 98.98 & 01.02 & $/$ & $/$ & $/$ & $/$ & $/$ & $/$ & ZAF \\
\multirow{2}{*}{$\mathbf{2}$} & $W t \%$ & 11.62 & $/$ & 36.00 & 01.28 & 03.13 & 24.73 & 01.15 & 22.10 & Correction \\
& $A t \%$ & 05.09 & $/$ & 55.05 & 01.29 & 02.83 & 21.53 & 00.72 & 13.49 & ZAF \\
\multirow{2}{*}{$\mathbf{3}$} & $W t \%$ & 14.23 & $/$ & 32.94 & 01.24 & 02.73 & 24.08 & 01.40 & 23.38 & Correction \\
& $A t \%$ & 06.46 & $/$ & 52.22 & 01.30 & 02.57 & 21.75 & 00.91 & 14.80 & ZAF \\
\hline
\end{tabular}

Fig. 9. SEM-EDS results of reduced pellets with $20 \%$ compound additive $\left(0.3\right.$ of basicity, reducing at $1200^{\circ} \mathrm{C}$ for $70 \mathrm{~min}$ at coal to dried pellets mass ratio of 2).

\section{Acknowledgements}

This work was financially supported by the National Key Technology R\&D Program of China (NO. 2013BAB03B04).

\section{REFERENCES}

1) M. Sánchez and M. Sudbury: J. Min. Metall. B, 49 (2013), 161.

2) B. Gorai, R. K. Jana and Premchand: Resour. Conserv. Recy., 39 (2003), 299.

3) G. A. Osborn, F. A. Garner and T. J. Veasey: Proc. Recycling of Metalliferous Materials Conf., Institution of Mining and Metallurgy, Birmingham, UK, (1990), 23.

4) W. J. Bruckard, M. Somerville and F. Hao: Miner. Eng., 17 (2004), 495.

5) A. Sarrafi, B. Rahmati, H. R. Hassani and H. H. A. Shirazi: Miner Eng., 17 (2004), 457.

6) X. Tong, B. Han, S. P. Ren and B. Yang: Appl. Mech. Mater., 496-500 (2014), 406

7) A. M. Arino and B. Mobasher: ACI Mater. J., 96 (1999), 68.

8) C. Shi, C. Meyer and A. Behnood: Resour. Conserv. Recy., 52 (2008), 1115 .

9) İ. Alp, H. Deveci and H. Süngün: J. Hazard. Mater., 159 (2008), 390.

10) R. K. Nadirov, L. I. Syzdykova, A. K. Zhussupova and M. T. Usserbaev: Int. J. Miner. Process., 124 (2013), 145.

11) X. Cheng, K. Zhao, Y. Qi, X. Shi and C. Zhen: J. Iron Steel Res. Int.,
20 (2013), 24.

12) B. Kim, S. Jo, D. Shin, J. Lee and S. Jeong: Int. J. Miner. Process., 124 (2013), 124

13) K. Li, S. Ping, H. Wang and W. Ni: Int J. Min Met Mater., 20 (2013), 1035 .

14) Y. Li, Z. Zhang, Z. Yuan and Y. Han: Metal Mine, (2006), 5 (in Chinese).

15) D. Zhu, V. Mendes, T. Chun, J. Pan, Q. Li, J. Li and G. Qiu: ISIJ Int., 51 (2011), 214.

16) J. H. Heo, B. Kim and J. H. Park: Metall. Mater. Trans. B, 44 (2013), 1352.

17) T. Jiang, M. Liu, G. Li, N. Sun, J. Zeng and G. Qiu: Chin. J. Nonferr. Metal., 20 (2010), 565 (in Chinese).

18) G. Li, S. Zhang, M. Rao, Y. Zhang and T. Jiang: Int. J. Miner. Process., 124 (2013), 26.

19) S. Bai, S. Wen, D. Liu, W. Zhang and Y. Xian: ISIJ Int., 51 (2011), 1601 .

20) J. Stjernberg, M. A. Olivas-Ogaz, M. L. Antti, J. C. Ion and B. Lindblom: Ceram. Int., 39 (2013), 791.

$21)$ D. Zhu, T. Chun and J. Pan: J. Univ. of Sci. Technol. Beijing, 22 (2011), 1325 (in Chinese).

22) Y. Xiao, Z. He, T. Chun, D. Zhu and J. Pan: 3rd Int. Symp. on HighTemperature Metallurgical Proc., John Wiley \& Sons, Inc., Orlando, Florida, (2012), 129

$23)$ D. Zhu, Y. Zhai, J. Pan, Y. Cui, Y. Tang and D. Xu: J. Central South Univ. (Sci. Technol.), 39 (2008), 1132 (in Chinese). 